\title{
DO INTRA AO INTERPESSOAL: A TRAJETÓRIA DAS PAIXÕES E UMA RETÓRICA DA
}

VALMIR FERREIRA DOS SANTOS JUNIOR* UNIVERSIDADE DE FRANCA

FRANCA - SÃO PAULO - BRASIL

FIGUEIREDO, Maria Flávia; GOMES, Acir de Matos; FERRAZ,

RESENHA Luana (Org.). Trajetória das paixões: uma retórica da alma. Franca: Unifran, 2020. 566p.

Em meio ao pandêmico ano de 2020, que transformou profundamente a forma com que concebemos a difusão do conhecimento no meio acadêmico - que hoje, mais do que nunca, acontece principalmente de forma remota-, o Grupo PARE (Pesquisa em Argumentação e Retórica), sediado na Universidade de Franca (UNIFRAN) e certificado pelo CNPq desde 2013, compôs a obra a qual esta resenha faz referência, Trajetória das paixões: uma retórica da alma.

O PARE é um grupo composto de pesquisadores que se encontram em diferentes níveis na carreira acadêmica. Tal diversidade possibilita um sistema de contribuição entre os seus membros, chamado de orientação em cascata. Por meio desse sistema, pessoas que se encontram em níveis acadêmicos mais avançados auxiliam e orientam colegas que também trilham o caminho acadêmico. À vista disso, o grupo conta com professores titulares, pósdoutores, doutores, mestres, especialistas, graduados e alunos de Iniciação Científica.

A atividade do grupo, até o presente momento, resultou em outras duas publicações: $O$ animal que nos habita: a retórica das paixões em Relatos Selvagens (2016); e Retórica e multimodalidade (2018). A obra a qual esta resenha alude foi organizada pelos professores doutores Maria Flávia Figueiredo (especialista em Linguística, Retórica, Língua Portuguesa e Língua Inglesa), Acir de Matos Gomes (especialista em Retórica e Direito) e Luana Ferraz (especialista em Retórica e Língua Portuguesa).

Em decorrência da atuação dos organizadores no Programa de Pós-Graduação em Linguística da Universidade de Franca (UNIFRAN), os trabalhos que compõe a obra são

\footnotetext{
* Doutorando em Linguística pela Universidade de Franca (UNIFRAN), bolsista da Fundação de Amparo à Pesquisa do Estado de São Paulo (FAPESP). E-mail: valmirferreiradossantosjunior@gmail.com.
} 
majoritariamente de autoria de mestrandos, doutorandos, mestres e doutores que fazem parte do Programa. Além disso, o livro conta, também, com capítulos de pesquisadores externos.

A obra, de acordo com a função dos autores que a compõe, permeia a seara da Retórica que, por sua vez, se alia à Linguística contemporânea em seus meandros e, portanto, é direcionada a todos analistas do discurso que se debruçam sobre as ferramentas argumentativas e persuasivas do texto, em especial àqueles que se interessam pelos desdobramentos passionais dos discursos de natureza retórica.

A trajetória das paixões: uma retórica da alma é um compilado teórico-analítico que se divide em 22 capítulos (redigidos em português e inglês). Logo após seu prefácio e sua apresentação, a líder do Grupo Pare e organizadora da obra, Maria Flávia Figueiredo, apresenta o capítulo introdutório, que introduz o fio condutor de toda a obra: a trajetória das paixões.

O conceito que dá título à obra, trajetória das paixões, decorre de uma das pisteis apresentadas por Aristóteles em sua Retórica. De acordo com o autor grego, existem fundamentalmente três meios de persuasão (pisteis), também vistos como o tripé retórico, que podem ser caracterizados da seguinte forma: ethos (a imagem que o orador, a figura responsável pela apresentação de um discurso, cria de si); $\log o s$ (o conteúdo o qual compõe o discurso, provas, argumentos, exemplos, histórias etc.); e pathos (o trabalho com as emoções, paixões, que têm a função de direcionar o campo emotivo do auditório em prol da aceitação do discurso apresentado pelo orador).

Ainda discutindo sobre as pisteis aristotélicas: o ethos pode servir como a ferramenta persuasiva que é responsável por angariar a confiança do auditório, quando o orador se apresenta, aos olhos desse auditório, como benevolente (eunoia), sincero (arete) e detentor de conhecimento (phronesis); o logos funciona de forma persuasiva quando a organização de um discurso é coerente, clara e objetiva, sob o ponto de vista retórico. Ademais, persuade-se pelos entremeios do logos quando os argumentos que constituem o discurso são verossímeis e encaminham ao convencimento pela racionalidade; o pathos é a ferramenta persuasiva de um discurso retórico que motiva o auditório a aderir à tese apresentada pelo orador por intermédio de caminhos psicológicos (passionais).

Dessa forma, pode-se observar de que maneira um discurso retórico encaminha um auditório à persuasão: ao aliar a confiança pelo orador e pelo discurso (por intermédio do ethos 
e do logos), a argumentação racional (intermediada pelas ferramentas do logos) e, principalmente, a argumentação passional (subsidiada pelos caminhos emocionais contidos no pathos).

O conceito ao qual a obra faz referência, a trajetória das paixões, é uma proposição que se insere no pathos e perscruta o caminho que uma paixão aristotélica percorre na psique e corpo humanos para a sua manifestação no homem. Tal proposição fundamenta-se em uma metodologia fenomenológica, aquela que observa certo fenômeno com o intuito de visualizar seu funcionamento, e, portanto, apresenta as engrenagens passionais da intricada máquina humana, um composto de razão e, primordialmente, emoção. A ideia conceitual da trajetória foi desenvolvida em diversos outros textos da pesquisadora e apresentada reformulada no capítulo inicial da obra a qual esta resenha faz alusão.

Em seus cinco estágios (disponibilidade, identificação, despertar da paixão, mudança de julgamento e ação), a trajetória pontua as etapas pela qual uma emoção percorre no auditório para a sua manifestação nos universos intra e interpessoal do homem. Por meio desse conceito, pode-se visualizar a forma com que a construção subjetiva de uma predisposição em relação a uma determinada paixão influencia na maneira com que um discurso é recebido por aqueles que testemunham sua apresentação. Ademais, a trajetória organiza, para o analista do discurso, as regras de um jogo extremamente complexo: a lide com as emoções humanas.

Após o capítulo introdutório, que apresenta, define e explica o conceito e seus cinco estágios, a obra se desdobra cinco eixos temáticos, que reúnem os trabalhos em função de suas temáticas, objetos de análise ou área de aprofundamento.

O primeiro eixo temático da obra pode ser intitulado 'direito' e abarca os seguintes capítulos: "O mover das paixões na sentença judicial" (Acir de Matos Gomes, Gabriel Campos Frade Machado e Lívia Furlan Telini) e "A impermanência das emoções: Sócrates e a trajetória das paixões" (Letícia Machel Lovo).

Nos dois capítulos desse eixo, os autores demonstram como as paixões podem estar presentes até mesmo em uma sentença, ou em um discurso do gênero retórico judicial, algo que para um auditório não especializado possa parecer incomum. Por meio desses capítulos, o leitor compreenderá que ações motivadas por paixões estão presentes em todas as esferas da atuação 
humana, até mesmo no campo jurídico, que pode parecer detentor de uma objetividade separada do campo emotivo.

O segundo eixo temático pode ser sintetizado pelos termos 'metalinguagem/ teoria retórica' e reúne os seguintes capítulos: “Auditório particular, disponibilidade e identificação: aproximações entre processos retóricos-identitários" (Alan Ribeiro Radi), “Trajetória das paixões: uma aplicação pedagógica" (Ana Lúcia Magalhães), "Imagens e figuras de construção na trajetória das paixões: aspectos cognitivos e funcionalidade retórica" (Antônio Suárez Abreu) e "De olho em Aquino: como a percepção provoca paixões" (Pedro Luiz Rodarte Gulke).

Por meio dos capítulos mencionados no segundo eixo, o leitor poderá compreender como a teoria retórica, e filosófica (no caso do texto motivado por São Tomás de Aquino), expande e fundamenta a estruturação da trajetória das paixões. Cada um dos capítulos apresenta uma perspectiva única no que concerne à relação que a Retórica mantém com a trajetória, seja por sinalizar de que forma o auditório se insere na proposição temática do livro, por observar a relação do orador e do auditório inseridos em um contexto pedagógico, por ponderar acerca da forma com que as figuras e narrativas auxiliam no processo do despertar passional, ou seja, por refletir e conectar a visão de Aquino à Retórica.

O terceiro eixo pode ser resumido pela temática da 'Sociologia' e têm em sua composição os seguintes capítulos: "Uma escolha de Sofia: a trajetória das paixões no discurso de médicos da linha de frente da Covid-19” (Ananias Agostinho da Silva e Maria Flávia Figueiredo), “As paixões dos vulneráveis: análise retórico-passional de relatos de pessoas em situação de rua” (Gabriel Henrique Haddad), “A força do pathos e sua trajetória na campanha call" (Mariana Ferreira Santos e Acir de Matos Gomes), "Acreditar é o que nos move: paixões do amor e da confiança como elementos de persuasão em um filme publicitário" (Priscila Antunes de Souza) e "O pathos dos degenerados: Rita Von Hunty e o despertar da paixão do amor" (Ticiano Jardim Pimenta).

O eixo em questão abarca a forma com que a Retórica, e mais precisamente a trajetória das paixões, funciona em seus desdobramentos interpessoais. Por meio de cada um dos textos desse eixo, o leitor encontrará a constatação de que as paixões aristotélicas são a chave-mestra que abre as portas do baú emocional da persuasão. Intermediada nas emoções, tal estratégia 
retórica se apresentará como um tesouro, ao qual o analista do discurso deve prestar atenção na lide com sua matéria analítica.

O quarto eixo da obra pode ser caracterizado pelas palavras-chave "poesia, música, cinema e literatura". Tal eixo abarca os seguintes capítulos: "Rasgar-se e remendar-se: a via crusis das paixões em Vidas Secas" (Daniela Rodrigues de Oliveira), "É proibido proibir: a paixão do ódio como estratégia retórica" (Delzio Marques Soares), "Em busca de uma essência mais verdadeira: a trajetória das paixões na canção "perfume do invisível"” (Farnei Santos), "Análise do filme Coringa sob a perspectiva da trajetória das paixões" (Sirlene Aparecida Pessalacia Barretto) e "How music makes us feel Alive: a pathways of passion analysis" (Valmir Ferreira dos Santos Júnior).

Os capítulos do eixo mencionado discutem a forma com que textos poéticos, na contemporaneidade - haja vista nossa sociedade multifacetada, funcionam como discursos retóricos ao angariar a adesão de seus auditórios ao barganhar na seara psicológica da constituição humana e ao despertar e propiciar desdobramentos passionais contundentes que levam o auditório dos textos poéticos a ações.

O quinto eixo do livro pode ser concebido por duas palavras: "Discurso religioso". Tal eixo abriga os seguintes capítulos: "No amor não existe medo: a trajetória das paixões no discurso do Papa João Paulo II" (Ana Cláudia Ferreira da Silveira e Maria Sílvia RodriguesAlves), "Fé passional: a trajetória das paixões no mito da criação" (Luan Marques Domingues e Valmir Ferreira dos Santos Júnior), "O humor no púlpito e o despertar da confiança” (Luana Ferraz) e “A trajetória das paixões na parábola do filho pródigo" (Luiz Alves de Souza).

Os textos desse último eixo temático que compõe a obra discutem as projeções passionais e a força do pathos, quando o orador habita a esfera discursiva religiosa. Como pode ser visto nos capítulos dessa linha temática, o trabalho com as emoções, em perspectiva discursiva, possui papel ímpar para a evangelização e para a adesão da tese proposta pelo orador. Em suas inúmeras particularidades, os textos desse eixo demonstram como a religião sempre bebeu da fonte retórica, uma vez que seu intuito é primordialmente persuadir.

Trajetória das paixões: uma retórica da alma é um livro que evidencia a riqueza das produções teóricas, no campo retórico, a nível nacional. Tanto na proposição inicial, da trajetória, quanto nos desdobramentos dos capítulos que se inspiram no conceito de Figueiredo, 
as reflexões analíticas e teóricas que a obra abarca comprovam a forma com que os pesquisadores brasileiros têm muito a contribuir para a Retórica dos dias de hoje. Tal aspecto também desvela como a teoria sistematizada por Aristóteles, na Era Clássica da humanidade, encontra matéria para transformar-se continuamente durante o tempo e a evolução da comunicação humana.

Por fim, convém atentar para a natureza da obra resenhada aqui, que revela que a relação do homem consigo e com outrem, ou seja, com seus universos intra e interpessoais, está intrinsecamente relacionada em um continuum. Em suma, o livro denota o infinito ciclo de relações que o homem mantém com seu interior e exterior. Sob a lupa retórica, pode-se observar que tal ciclo funciona, para o auditório retórico, como uma forma de interpretar, construir e reconstruir suas particularidades, disposições e visões em relação ao mundo.

Recebido em: 23/11/2020 - Aprovado em: 04/01/2021 